Ә OPEN ACCESS

\title{
Dinamika Komunikasi Politik Pada Pemilihan Presiden Di Indonesia
}

\author{
* Samsul Rani \\ * Komunikasi dan Penyiaran Islam, Fakultas Dakwah dan Ilmu Komunikasi, \\ Banjarmasin, Indonesia \\ *Email; samsulrani@ymail.com
}

\begin{abstract}
The dynamics of political communication occurred through phenomena before and after the presidential election in Indonesia, both conducted by political elites, party supporters, and the public to win the presidential candidates and vice-presidential candidates he supports. This can be seen from the form of political communication in the campaign, political attitudes in addressing the vote acquisition, and post-election political communication. Political communication through campaigns using digital media, especially social media such as Twitter, Whatsapp, Facebook, Instagram, and other media has given a very significant influence in gaining public support, but negative campaigns and black campaigns (hoax) cannot be avoided, even in the legal sphere. Political communication at the end of the voting is stated through a victory speech through political speeches based on different survey results, namely quick count and exit polls. The speech added to the polemic about the validity and honesty in the implementation of the General Election because of the very significant difference in votes in Indonesia. Political communication on the determination of the results of the real count resulted in an unelected presidential candidate bringing the case to the realm of law, namely the Constitutional Court court to cancel the victory of the elected presidential candidate. Political communication after the determination of the results of the election, election is that the elected president reconciles the nonelected presidential candidates to eliminate friction in the community. Besides, the coalition party supporting the elected president lobbied both fellow supporters and the elected president to get a ministerial position in the cabinet and the parliament.
\end{abstract}

KEYWORDS political communication; electoral; digital media 
ABSTRAK

Telah terjadi dinamika komunikasi politik melalui fenomena-fenomena sebelum dan sesudah dilaksanakannya pemilihan presiden di Indonesia, baik yang dilakukan oleh elite politik, partai pendukung, maupun masyarakat untuk memenangkan calon presiden dan calon wakil presiden yang didukungnya. Hal ini dapat dilihat dari bentuk komunikasi politik dalam kampanye, sikap politik dalam menyikapi perolehan suara, dan komunikasi politik pasca Pemilu. Komunikasi politik melalui kampanye dengan menggunakan media digital khususnya media sosial seperti Twitter, Whatsapp, Facebook, Instagram dan media lainnya telah memberikan pengaruh sangat signifikan dalam memperoleh dukungan masyarakat, tetapi negative campaign dan black campaign (hoaks) tidak dapat dihindarkan, bahkan sampai ke ranah hukum. Komunikasi politik pada saat selesai pemungutan suara dinyatakan lewat pidato kemenangan melalui pidato politik dilakukan berdasarkan hasil survei yang berbeda yaitu quick count dan exit poll. Pidato tersebut menambah polemik tentang keabsahan dan kejujuran dalam pelaksanaan Pemilu karena selisih suara yang sangat signifikan di Indonesia. Komunikasi politik pada penetapan hasil real count mengakibatkan calon presiden tidak terpilih membawa kasus tersebut ke ranah hukum yaitu pengadilan Makamah Konstitusi untuk membatalkan kemenangan calon presiden terpilih. Komunikasi politik pasca penetapan hasil pemilihan terpilih adalah presiden terpilih melakukan rekonsiliasi kepada calon presiden tidak terpilih untuk menghilangkan friksi-friksi dimasyarakat. Selain itu partai koalisi pendukung presiden terpilih melakukan lobi, baik kepada sesama partai pendukung maupun ke presiden terpilih untuk mendapatkan jabatan menteri dalam kabinet maupun di parliament.

KATA KUNCI komunikasi politik; pemilihan umum; media digital

\section{Pendahuluan}

Pemilihan Umum (Pemilu) pada Tahun 2019 merupakan Pemilu serentak pertama yang dilaksanakan oleh Pemerintah Indonesia, karena selain memilih anggota DPR, DPD, DPR Provinsi, dan DPR Kabupaten/Kota, juga memilih Presiden dan Wakil Presiden (Pilpres). Kebijakan Pemilu serentak merupakan

Putusan Makamah Konstitusi (MK) Nomor 14/PUU-XI/2013. MK mempertimbangkan bahwa Pemilu serentak akan dapat menghilangkan bentuk bargaining dan negosiasi politik. Selain itu juga akan membuat Pemilu akan menjadi lebih bersih dari kepentingan negosiasi politik dalam menentukan pasangan calon presiden (capres) dan calon wakil presiden (cawapres) yang akan didukung.

Pertimbangan MK dengan mengeluarkan putusan Pemilu serentak ternyata tidak sesuai harapan, lobi atau bargaining politik justeru terjadi menjelang penentuan capres dan cawapres, yang pada akhirnya hanya terdapat dua pasangan capres dan cawapres, akibatnya terjadi gesekan harizontal di 
masyarakat bahkan menimbulkan konflik, karena masyarakat Indonesia terbelah menjadi dua kubu pendukung pasangan calon pada Pilpres tersebut.

Pasangan capres dan cawapres yang ikut Pemilu terbagi dalam dua koalisi partai, yaitu pasangan Joko Widodo dan Ma'ruf Amin (Jokowi- Ma'ruf) sebagai petahana dengan Koalisi Indonesia Kerja didukung oleh 10 partai yaitu Partai PDI Perjuangan, Partai PKB, Partai Hanura, Partai Golkar, Partai Nasdem, Partai PPP, Partai Perindo, Partai PSI, Partai PKPI, dan PBB. Sedangkan penantang adalah pasangan Prabowo Subianto dan Sandiaga Uno (Prabowo-Sandi) dengan Koalisi Indonesia Adil Makmur didukung oleh 5 partai yaitu Partai Gerindra, Partai PKS, Partai Berkarya, Partai Demokrat, dan Partai PAN.

Partai politik sebagai pengusung pasangan calon dalam Pilpres tentu telah melakukan komunikasi politik yang efektif dan efisien sehingga diharapkan mampu menampilkan kesan dan pesan politik kepada partai koalisi maupun konstituen baik melalui media cetak maupun elektronik, sehingga menjadi pendukung yang solid terhadap pasangan calon tersebut. Hal inilah yang pada akhirnya menimbulkan dua kubu dalam Pilpres, yaitu kubu petahana dengan slogan nasionalisme pengusung kebhinekaan dan kubu penantang dengan politik identitas eksklusivisme agama. Pertarungan dua kubu tersebut bukan hanya terjadi pada elite-elite politik dan partai, tetapi juga sampai ke massa pendukung. Akibatnya perang teknologi komunikasi dan informasi pendukung pasangan calonpun tak terhindarkan, yang biasa disebut dengan virtual election communication. Ivanka (dalam Boicu, 2017:35) berpendapat bahwa virtual election communication is a kind of virtual political communication which appears in the virtual environment in the form of websites, blogs, social networks, video clips, virtual forums and so on.

Begitu pula apa yang disampaikan oleh Kiyohara tentang ciri khas Pemilu di Amerika yang mana kampanye tidak terlepas dari teknologi komunikasi dengan berbagai platforms. Dia mengatakan bahwa campaigning increasingly is driven by emergent communications technologies. Digital media-forms of communication that can be transmitted online or over the Internet, such as websites, blogs, online news platforms, social media, and apps-have become hallmarks of American elections (Kiyohara, 31:2018). Walaupun warga negara banyak 
menggunakan internet untuk tujuan politik termasuk dalam kampanye capres dan cawapres yang didukungnya, tetapi hal ini tidak berpengaruh signifikan terhadap mobilisasi massa. Hal ini disampaikan oleh Kaid (528:2004) bahwa research shows that citizens are turning to the Internet, but the same politically interested citizens using traditional media are more likely to use the Internet for political purposes. So, although politicians and citizens are using the Internet, not much real change in mobilization.

Sehubungan dengan itu, telah terjadi dinamika komunikasi politik melalui fenomena-fenomena sebelum dan sesudah dilaksanakannya Pemilu serentak di Indonesia, khususnya pada Pilpres, baik yang dilakukan oleh elite politik, partai pendukung, maupun masyarakat untuk memenangkan capres dan cawapres yang didukungnya. Hal ini dapat dilihat dari bentuk komunikasi politik dalam kampanye, sikap politik dalam menyikapi perolehan suara, dan komunikasi politik pasca Pemilu. Faktor komunikasi politik dari berbagai persfektif inilah yang pada akhirnya menimbulkan dinamika komunikasi pada Pemilu yang dapat menimbulkan konflik kepentingan untuk sebuah kekuasaan.

\section{Hasil Penelitian dan Pembahasan \\ Komunikasi Politik Dalam Kampanye}

Komunikasi politik mempunyai peranan yang penting dalam Pemilu khususnya dalam kampanye, Perloff berpendapat bahwa political communication is the process by which language and symbols, employed by leaders, media, or citizens, exert intended or unintended effects on the political cognitions, attitudes, or behaviors of individuals or on outcomes that bear on the public policy of a nation, state, or community (Perloff, 2014:30). Pada era teknologi komunikasi informasi sekarang ini, kampanye melalui media digital tidak dapat dihindarkan seperti yang disampaikan oleh Bennett \& lyengar (2008) bahwa the technological revolution has had two major influences. It has vastly increased the supply of information, with conventional media, websites galore, blogs, and politically oriented social media posts offering a plethora of facts and opinions about politics. Technology has also greatly expanded choices, with a wealth of sources and channels available to people (dalam Perloff, 2014:38). 
Kampanye pasangan capres dan cawapres melalui media digital khususnya media sosial seperti Twitter, Whatsapp, Facebook, Instagram dan media lainnya dapat memberikan pengaruh sangat signifikan dalam memperoleh dukungan masyarakat dan juga dapat meminimalisasi anggaran biaya kampanye. Hal ini seperti yang disampaikan oleh Silvia (2017:3) bahwa digital advertising can sustain the efforts of candidates who do not have suffi cient fi nancial resources to promote their political programmes, since communication on blogs, forums, social networks or other online communication tools does not require the spending of substantial funds. Wring (144:2019) melihat dari persfektif lain bahwa teknologi komunikasi sangat cocok untuk karakteristik model desentralisasi, seperti yang ia katakan bahwa the digital age and its communication technologies are well suited to a decentralised model of political campaign engagement that shares authority within a more party-focused campaign.

Para elite politik di Indonesia telah lama memanfaatkan media sosial untuk berbagai informasi dengan pemilihnya maupun masyarakat secara umum, baik melalui media digital maupun media sosial lainnya, hal ini sangat mendukung perolehan suara bagi pasangan capres dan cawapres yang didukungnya. Silvia (2017:3) berpendapat bahwa political actors are beginning to understand that they can benefi trom using the Internet as a means of transmitting electoral messages in a complementary way to traditional media and direct political communication. Pernyataan ini juga didukung oleh Wring (173:2019) yang mengatakan bahwa momentum's digital media tools were designed to encourage and empower activists to get involved and to then go out to communicate with other voters.

Apa yang telah dilakukan oleh elite politik dalam penggunaan media sosial bukan tanpa alasan, karena menurut laporan survei HootSuite pada Januari 2019 bahwa pengguna media sosial aktif di Indonesia sebanyak 150 juta orang (naik $15 \%$ atau sekitar 20 dari tahun 2018), sedangkan pengguna media sosial mobile sebanyak 130 juta (naik 8,3\% atau sekitar 10 dari tahun 2018), dengan platforms media sosial yang paling aktif berdasarkan persentase pengguna internet yang menggunakan setiap platform yaitu Youtube 88\%, Whatsapp 83\%, Facebook 81\%, Instagram 80\%, dan Twitter 52\% (HootSuite, 2019). Melalui media sosial inilah kampanye para pendukung pasangan capres dan cawapres dari kedua 
kubu melakukan positive campaign, negative campaign, bahkan black campaign (hoaks) melalui perang tagar \# (hashtag) sebagai bagian dari propaganda politik.

Kementerian Komunikasi dan Informatika (Kominfo) melalui Siaran Pers No. 92/HM/KOMINFO/04/2019 Tentang Kominfo Identifikasi 1.645 Hoaks Terkait Pemilu Serentak 2019 pada Tanggal 27 April 2019, menginformasikan bahwa berdasarkan catatan Kominfo sejak bulan Agustus 2018 hingga 25 April 2019 teridentifikasi sebanyak 1.645 content hoaks. Sepanjang masa kampanye capres cawapres sejak Agustus 2018, Kementerian Kominfo telah mengais content hoaks yang ditujukan kepada Capres Joko Widodo maupun Prabowo Subianto. Sementara hoaks yang ditujukan kepada Cawapres KH. Ma'ruf Amin maupun Sandiaga Uno, hanya sedikit. (Kominfo, 2019).

Kasus hoaks tersebut bahkan sampai menjadi kasus pidana karena dianggap melanggar Undang-undang No. 11 tahun 2008 tentang Informasi dan Transaksi Elektronik (ITE). Oleh karena itu strategi untuk membuat pesan politik dalam kampanye Pilpres menjadi tangungjawab penting bagi partai pendukung serta pasangan capres dan cawapres, agar makna pesan dapat diterima secara efektif oleh constituen, dan tidak tersandung masalah hukum. Huckfeldt (1995:107) berpendapat bahwa citizens obtain political information from a great many sources, politicians speeches, media reports, mass mailings, but they also obtain it from one another through various forms and means of social interaction. Not all information obtained through social interaction comes via the means of political discussion. Some of it comes from lapel pins, yard signs, and bumper stickers. Selain itu media yang menjadi partisan capres dan cawapres juga dikhwatirkan membuat berita hoak, seperti yang disampaikan oleh Wring (127:2019) bahwa the panic over social media effect on political journalism-in particular the liberal establishment's over-egged concern over alternative outlets peddling 'fake news'deserves attention.

Komunikasi politik lewat media sosial pada Pilpres menghadirkan banyak pertentangan dua kubu yang dilakukan oleh elite partai, tim pemenangan, maupun relawan. Hal ini dapat dilihat dari content media sosial yang cenderung memiliki sifat provokasi yang membenturkan kelompok masyarakat, yang pada akhirnya pola hubungan antar warga tidak harmonis akibat perbedaan pilihan 
capres dan cawapres. Kondisi perpecahan dimasyarakat dalam Pilpres diperparah juga oleh media massa baik cetak maupun elektronik yang menjadi partisan, sehingga informasi yang disajikan terdistorsi oleh framing media yang mendukung salah satu pasangan capres dan cawapres.

Friksi yang terjadi dimasyarakat dalam Pilpres sebenarnya terjadi akibat literasi media khususnya literasi media digital yang masih kurang di Indonesia. Masyarakat cenderung sangat mudah mempercayai sebuah informasi atau berita yang diterimanya, sebelum melakukan cross check atau memvalidasi informasi tersebut, hal ini sebagai akibat masyarakat sudah menentukan pilihan dan memberikan dukungan kepada capres dan cawapres tertentu. Sehingga apa yang disajikan media sosial tentang capres dan cawapres yang didukungnya adalah sebuah kebenaran, sedangkan rivalnya dianggap sebuah kesalahan. Inilah yang pada akhirnya "perang" content di media sosial tidak dapat dihindari melalui negative campaign dan black campaign (hoaks).

Berbagai bentuk kampanye baik positif, negatif, maupun kampanye hitam tidak bisa dihindari dalam Pemilu, hal ini disebabkan karakteristik pendukung yang memiliki latar belakang yang berbeda, baik umur, pendidikan, maupun profesi. Hal ini dipertegas oleh pendapat Marc bahwa despite this general prevalence of electoral participation across the population, some forms of inequality and stratification do remain present. Partly these find their origin in individual background characteristics, such as partisanship, age, profession, level of education, or political interest (dalam Kai, 2017:242). Robert melihat dari persfektif lain kecenderungan pemilih dalam menentukan hak politiknya, bahwa ideology is theoretically and empirically among the most central components of individuals' belief systems. Indeed, ideology is believed to influence virtually every political orientation, including (but not limited to) issue attitudes (dalam Kai, 2017:493).

Sedangkan Martin menilai masyarakat terbelah menjadi dua kubu pendukung sebagai akibat latar belakang dari agama capres dan cawapres atau juga dari ideologi agama partai pendukung, bahwa one way is that religious voters are more likely to vote for particular candidates or parties than less religious or nonreligious voters. Another way is that voters adhering to different religious denominations tend to support different candidates or parties (dalam Kai, 2017:200). 
Lebih jauh ia mengatakan bahwa fenomena politik dalam Pemilu sebagai akibat pillarisation, hal ini memperkuat asumsi bahwa perolehan suara dalam Pemilu sangat dipengaruhi oleh faktor agama, seperti pernyataan dia bahwa another linkage between membership in religious groups and voting may be created by a phenomenon that is known as pillarisation. Pillarised politics means that society is divided in mutually exclusive segments that are characterised not only by particular beliefs and/or ways of life but also by segmental organisations that take care of many aspects of life (dalam Kai, 2017:203).

\section{Komunikasi Politik Dalam Menyikapi Quick Count}

Hasil Pemilu khususnya perhitungan suara pada Pilpres yang dilaksanakan pada tanggal 17 April 2019 sangat ditunggu para elite partai maupun masyarakat pendukung pasangan capres dan cawapres. Hasil perhitungan suara untuk Pilpres dapat dilakukan sebelum real count yang dilakukan oleh Komisi Pemilihan Umum (KPU) yaitu melalui quick count. Berdasarkan putusan MK bahwa ketentuan batas waktu menyampaikan hasil quick count adalah paling cepat 2 (dua) jam setelah selesai pemungutan suara di wilayah Indonesia bagian barat sebagaimana diatur dalam Pasal 449 ayat (5) UU 7/2017. Dengan demikian bahwa pengumusan hasil quick count hanya boleh publikasikan pada pukul 15.00 WIB.

Keputusan MK ini berdasarkan pertimbangan diantaranya adalah 1). Dikhawatirkan pada saat hasil quick count langsung dipublikasikan, ada sejumlah masyarakat yang belum menyalurkan hak pilihnya di Wilayah Indonesia Barat, 2). Bila hasil quick count langsung dipublikasikan, maka hal tersebut bisa memengaruhi pemilih yang belum menggunakan hak suaranya, 3). Berpotensi memengaruhi pilihan sebagian pemilih yang bisa jadi mengikuti pemungutan suara dengan motivasi psikologis 'sekadar' ingin menjadi bagian dari pemenang, 4). Mempertimbangkan kemungkinan lembaga survei dan media yang mempublikasikan hasil quick count berafiliasi dengan pasangan calon tertentu (Kompas, 2019).

Hasil quick count yang dirilis oleh 12 lembaga survei ternyata memenangkan kubu petahana yaitu pasangan Joko Widodo dan Ma'ruf Amin. Kemenangan kubu petahana dari quick count tersebut ditindak lanjuti oleh pidato 
politik yang dilakukan oleh Joko Widodo bahwa meminta para pendukungnya untuk tidak bereaksi mendeklerasikan kemenangan Pilpres sebelum real count yang dilakukan oleh KPU diumumkan. Pada waktu yang hampir bersamaan pasangan Prabowo Subianto dan Sandiaga Uno juga mendeklerasikan kemenangan mereka dalam Pilpres berdasarkan survei yang mereka miliki.

Pidato kemenangan dilakukan oleh Prabowo Subianto dengan argumentasi bahwa mereka telah melakukan survey sendiri dengan metode exit poll. Perbedaan metode perhitungan cepat perolehan suara inilah yang pada akhirnya membuat elite partai, tim pemenang, dan tim relawan saling melakukan claim kemenangan. Hal ini menambah polemik di grass root para pendukung pasangan capres dan cawapres. Tudingan terhadap beberapa lembaga survei yang memenangkan pasangan Joko Widodo dan Ma'ruf Amin dalam perolehan suara di quick count sebagai lembaga survey bayaran tidak dapat dihindari, hal ini dilakukan untuk counter attack perbedaan suara yang sangat signifikan dari hasi quick count, dan juga melakukan counter argument bahwa pasangan Prabowo Subianto dan Sandiaga Uno adalah pemenang dalam pemilu berdasarkan survei yang mereka lakukan sendiri melalui metode exit poll. Pada akhirnya kedua pasangan capres dan cawapres tidak dapat melakukan claim kemenangan hanya berdasarkan hasil lembaga survei tersebut, tanpa menunggu real count yang dilakukan oleh KPU.

\section{Komunikasi Politik Dalam Penetapan Hasil Pilpres}

Pada akhirnya, siapa pun yang terpilih menjadi presiden dan wakil presiden republik Indonesia berdasarkan hasil resmi perhitungan KPU, diharapkan rakyat Indonesia kembali merajut persatuan dan kerukunan demi masa depan bangsa dan menghapus gap perbedaan dan bersatu dalam ruang bersama, karena pada hakikatnya kemenangan dari pesta demokrasi ini adalah kemenangan seluruh rakyat Indonesia, dari rakyat, oleh rakyat, dan untuk rakyat (KPU, 2019).

Penetapan hasil perhitungan real count yang dilakukan oleh KPU pada tanggal 21 Mei 2019 menetapkan pasangan capres dan cawapres Joko Widodo dan Ma'ruf Amin sebagai pemenang Pemilu, dengan peroleh suara 85.607.362 
$(55,5 \%)$ dari total nasional yang unggul di 21 provinsi, sedangkan pasangan Prabowo Subianto dan Sandiaga Uno memperoleh suara 68.650 .239 (44,5\%) yang unggul di 13 provinsi (Republika, 2019).

Hasil penetapan kemenangan pasangan petahana tersebut dianggap sebagai Pemilu yang penuh kecurangan, hal ini berdasarkan beberapa argumentasi dari pihak lawan, diantaranya adalah tuduhan memanfaatkan kekuasaan untuk mengintervensi birokrat dan memanfaatkan birokrasi, sampai dengan memanfaatkan program-program kebijakan pemerintah yang pro masyarakat menjelang Pemilu. Para elite partai, tim pemenang, dan tim relawan Prabowo Subianto dan Sandiaga Uno menyematkan istilah tuduhan kecurangan tersebut dengan model Terstruktur, Sistematis, dan Masif (TSM), dan mereka meminta masyarakat pendukung untuk terus memperjuangkan kemenangan versi mereka dari hasil exit poll.

Penetapan real count oleh KPU membuat grass root masa pendukung pasangan yang kalah dalam Pilpres tidak menerima, yang pada akhirnya melakukan demonstrasi dengan sasaran kantor Komisi Pemilihan Umum (KPU) dan Badan Pengawas Pemilu (Bawaslu), hal ini akhirnya menimbulkan korban jiwa. Harvey \& Mukherjee (2018:1) menyatakan bahwa the risk of popular protest is one of the few deterrents against election manipulation in authoritarian regimes and unconsolidated democracies. Hasil penelitiannya menyatakan bahwa data dari pemilu di 108 negara, dari tahun 1980 hingga tahun 2004, menunjukkan bahwa pilihan taktik manipulasi pemilu oleh rezim mempengaruhi kemungkinan protes pasca pemilihan.

Fenomena komunikasi politik dalam menyikapi kekalahan dalam Pemilu tersebut sebenarnya sudah dinyatakan oleh oleh Perloff bahwa in most political contexts, all three influence agents-elites, media, and public-interact in complex ways. The drama of political communication involves a trifecta: leaders, media, and citizens symbolically jousting among themselves and framing problems in different ways (Perloff, 2014:35). Beberapa tokoh nasional dan elite partai dari kubu koalisi pasangan Joko Widodo dan Ma'ruf Amin meminta pasangan capres dan cawapres Prabowo Subianto dan Sandiaga Uno untuk menenangkan massanya, agar polemik tidak berkepanjangan karena dapat menyebabkan perpecahan 
dalam bangsa.. Selain itu diharapkan ketidakpuasan pasangan yang kalah dalam Pemilu dapat menempuh jalur hukum melalui Makamah Konstitusi (MK). Prabowo Subianto akhirnya melakukan komunikasi politik kepada masyarakat pendukungnya, untuk tidak melakukan demontrasi dan melakukan tindakan anarki, serta membawa kasus keputusan KPU tentang pemenang Pilpres kejalur hukum atau menggugat hasil Pilpres tersebut.

Persidangan yang dilakukan oleh MK terhadap gugatan hasil Pilpres tersebut menghasilkan keputusan bahwa menolak seluruh gugatan permohonan pasangan Prabowo Subianto dan Sandiaga Uno, dengan argumentasi bahwa pihak penggugat tidak bisa membuktikan selisih perolehan suara dan tuduhan Pemilu yang dilakukan penuh kecurangan melalui metode TSM, hasil persidangan ini dibacakan pada Tanggal 27 Mei 2019. Berdasarkan kekalahan gugatan tersebut membuat Prabowo melakukan pidato politik dengan memuat empat point utama yaitu, 1). Menghormati Putusan MK, 2). Memikirkan Keutuhan Bangsa dan Negara, 3). Menguatkan Seluruh Pendukungnya, dan 4). Mengupayakan langkah hukum yang lain. Pernyataan komunikasi politik Prabowo tersebut tidak menurunkan ketegangan diantara massa kubu pendukung kedua pasangan capres dan cawapres. Friksi di masyarakat masih terjadi, konten di media sosial masih pro kontra terhadap hasil penetapan kemenangan pasangan Joko Widodo dan Ma'ruf Amin. Oleh karena itu untuk menghindari konflik dan perpecahan yang berkepanjangan ditengah masyakarat, Joko Widodo mengirim utusan untuk melobi elite partai koalisi Prabowo agar bisa melakukan pertemuan dengan Prabowo, dengan maksud melakukan rekonsiliasi agar ketegangan dimasyarakat bisa dihilangkan.

\section{Komunikasi Politik Pasca Penetapan Hasil Pilpres}

Pertemuan Joko Widodo dengan Prabowo Subianto pasca penetapan hasil Pilpres oleh KPU dilakukan pada Tanggal 13 Juli 2019, pertemuan ini hasil lobi politik yang dilakukan oleh tokoh tokoh nasional yang dimaksudkan untuk menghentikan friksi dimasyarakat Indonesia yang selama ini sudah terpecah menjadi dua kubu pendukung pasangan capres dan cawapres. Pertemuan yang dilakukan oleh presiden terpilih dengan rivalnya tersebut dimaksudkan untuk 
rekonsiliasi, karena "perang" yang dilakukan massa pendukung melalu media sosial seperti Istagram, Facebook, Whatsapp, Twitter, dan media lainnya masih terus berlangsung.

Pertemuan yang dilakukan diruang publik yaitu MRT atau Stasiun Kereta Api telah membuat sebuah pernyataan politik dari Prabowo untuk menerima kemenangan pasangan Joko Widodo dan Ma'ruf Amin sebagai presiden dan wakil presiden Indonesia. Pernyataan tersebut juga meminta massa pendukungnya melakukan hal yang sama, sehingga persatuan dan kesatuan bangsa tetap terjaga. Tetapi pada kenyataannya tindakan Probowo yang menghadiri undangan Jokowi Widodo untuk rekonsiliasi tersebut tidak diapresiasi oleh elite elite politik pendukung pasangan Prabowo-Sandi. Elite politik tersebut menginginkan rekonsiliasi dengan sebuah "syarat" atau bargaining politik tertentu, dan secara nyata mereka menginginkan beberapa "kursi" kementerian dikabinet yang akan dibentuk oleh pasangan presiden dan wakil presiden terpilih.

Rekonsiliasi dengan syarat ini telah menimbulkan polemik dalam koalisi partai pendukung Jokowi, kontra terhadap pemberian jabatan menteri dalam kabinet baru tidak dapat dihindarkan. Elite partai yang mendukung diberikan jabatan menteri untuk koalisi Prabowo berargumentasi agar rekonsiliasi benar benar terjadi dari elite politik sampai grass root pendukung pasangan PrabowoSandi. Sedangkan elite partai yang tidak mendukung rekonsiliasi dengan syarat berargumentasi bahwa pihak elite-elite partai pendukung Prabowo tidak pernah berjuang bersama untuk kemenangan pasangan Jokowi-Ma'ruf.

Pada dasarnya komunikasi politik yang dilakukan oleh elite partai pendukung pemenang pasangan capres terpilih untuk mendapatkan jabatan dalam pemerintahan tidak dapat dihindarkan dalam sebuah Pemilu. Hal serupa juga terjadi partai pendukung Jokowi, mereka mengharapkan mendapatkan pembagian jabatan menteri, bukan hanya sekedar jabatan saja bahkan sampai pada jumlah "kursi" menteri yang berhak mereka dapatkan. Tentu politik balas jasa seperti ini adalah yang lumrah pada setiap Pilpres di negara manapun, bukan hanya pada jabatan menteri tetapi juga pada jabatan jabatan penting lainnya di pemerintahan dan parlemen. 
Begitu pula di Indonesia, politik balas jasa untuk partai pendukung bukan hanya diberikan pada kursi di tingkat eksekutif, juga bargaining dan lobi pada kursi-kursi level yang lebih tinggi yaitu di tingkat legislatif seperti Ketua dan Wakil Ketua Majelis Permusyawaratan Rakyat (MPR) dan Dewan Perwakilan Rakyat (DPR), bahkan pada kenyataannya balas jasa tersebut juga diberikan kepada partai pendukung untuk jabatan tinggi pada tingkat yudikatif. Politik balas jasa melalui lobi partai pendukung bukan hanya terjadi pada jabatan yang tinggi, juga pada jabatan yang rendah dan diluar parlemen seperti ketua komisikomisi dalam DPR, Duta Besar, dan BUMN.

\section{Simpulan}

Komunikasi politik melalui kampanye pasangan capres dan cawapres dengan menggunakan media digital khususnya media sosial seperti Twitter, Whatsapp, Facebook, Instagram dan media lainnya dapat memberikan pengaruh sangat signifikan dalam memperoleh dukungan masyarakat, tetapi negative campaign dan black campaign (hoaks) tidak dapat dihindarkan, bahkan sampai ke ranah hukum.

Komunikasi politik pada saat selesai pemungutan suara dinyatakan lewat pidato kemenangan yang dilakukan oleh capres kedua kubu. Pernyataan kemenangan melalui pidato politik dilakukan berdasarkan metode hasil survei yang berbeda yaitu quick count dan exit poll. Pidato tersebut menambah polemik tentang keabsahan dan kejujuran dalam pelaksanaan Pemilu karena selisih suara yang sangat signifikan.

Komunikasi politik pada penetapan hasil real count yang dilakukan KPU yang telah menetapkan kemenangan pasangan Jokowi-Ma'ruf tersebut, oleh Prabowo dianggap sebagai Pemilu yang penuh kecurangan, sehingga membawa kasus tersebut ke ranah hukum yaitu pengadilan Makamah Konstitusi untuk membatalkan kemenangan itu, dan meminta pendukungnya untuk terus mengawal kasus tersebut.

Komunikasi politik pasca penetapan hasil Pilpres, Jokowi melakukan proposal untuk rekonsiliasi yang disambut oleh Prabowo untuk menghilangkan friksi-friksi dimasyarakat. Selain itu partai koalisi pendukung Jokowi melakukan 
lobi, baik kepada sesama partai pendukung maupun ke Jokowi khususnya untuk mendapatkan jabatan menteri dalam kabinet maupun jabatan di DPR dan MPR.

\section{Referensi}

Andi.Link. Hootsuite (We are Social): Indonesian Digital Report 2019. Diakses pada Juli 20, 2018, dari https://andi.link/hootsuite-we-are-social-indonesiandigital-report-2019/.

Cole J. Harvey \& Paula Mukherjee. (2018). Methods of Election Manipulation and the Likelihood of Post-Election Protest. Government and Opposition (2018), 0, 1 23. doi:10.1017/gov.2018.38.

Dominic Wring, Roger Mortimore, Simon Atkinson. (2019). Political Communication in Britain: Campaigning, Media and Polling in the 2017 General Election. Switzerland: Palgrave Macmillan.

Kominfo. Pemilu 2019 dalam Pusaran Hoaks, Bukti Lemahnya Literasi Digital?. Diakses pada Juli 20, 2018, dari https://www.kominfo.go.id/content/detail/18231/pemilu-2019-dalampusaran-hoaks-bukti-lemahnya-literasi-digital/0/sorotan media.

Kompas. Ini Alasan MK Baru Perbolehkan Publikasi "Quick Count" Pukul 15.00 WIB. Diakses pada Juli 20, 2018, dari https://nasional.kompas.com/read/2019/04/16/13105091/ini-alasan-mkbaru-perbolehkan-publikasi-quick-count-pukul-1500-wib.

Lynda Lee Kaid. (2004). Handbook Of Political Communication Research. London: Lawrence Erlbaum Associates.

Republika. Pidato Kemenangan, Jokowi: Mari Hargai Hasil Pemilu. Diakses pada Juli 20, 2018, dari https://nasional.republika.co.id/berita/nasional/politik/pruevm409/pidat o-kemenangan-jokowi-mari-hargai-hasil-pemilu.

Richard M. Perloff. (2014). The Dynamics Of Political Communication: Media and Politics in a Digital Age. New York: Routledge, Taylor \& Francis Group.

Robert Huckfeldt \& John Sprague. (1995). Citizens, Politics, And Social Communication: Information And Influence In An Election Campaign. Australia: Cambridge University Press.

Ruxandra Boicu, Silvia Branea, Adriana Stefanel. (2017). Political Communication and European Parliamentary Elections in Times of Crisis: Perspectives from Central and South-Eastern Europe. United Kingdom: Palgrave Macmillan.

Shoko Kiyohara, Kazuhiro Maeshima, Diana Owen. (2018). Internet Election Campaigns in the United States, Japan, South Korea, and Taiwan. Switzerland: Palgrave Macmillan. 